\title{
INFLUÊNCIA DO SÍTIO NO DESENVOLVIMENTO DO Pinus taeda AOS 22 ANOS: 1. CARACTERÍSTICAS FÍSICO-HÍDRICAS E QUÍMICAS DO SOLO
}

\author{
Renato Antonio Dedecek*, Ivone Satsuki Namikawa Fier**, Randy Speltz**, \\ Luís Carlos de Souza Lima*** \\ *Eng. Agrônomo, Ph.D., Embrapa Florestas - dedecek@cnpf.embrapa.br \\ **Eng. Florestal, M.Sc., Klabin S.A. - namikawa@klabin.com.br - randys@klabinpr.com.br \\ ***Tec. Florestal, Klabin S.A. - luiscarlos@klabinpr.com.br \\ Recebido para publicação: 04/04/2007 - Aceito para publicação: 06/12/2007
}

\begin{abstract}
Resumo
Para avaliar a influência do sítio no crescimento de Pinus taeda, foram selecionados, em área de plantio comercial, no município de Telêmaco Borba (PR), oito sítios com essa espécie aos 22 anos de idade, diferenciados pelo tipo de solo (Latossolo e Cambissolo), textura (argilosa e média) e vegetação original (campo e floresta). Para a caracterização dos sítios, foram realizadas avaliações dendrométricas de 50 árvores por sítio e coleta de solo em 3 profundidades para análises. Selecionaram-se 3 árvores médias por sítio, nas quais foram medidas altura total, altura para serraria e para celulose e DAP. O principal fator que influenciou o volume de madeira para serraria foi a fase de vegetação original, sendo os maiores DAPs encontrados em áreas provenientes de floresta. Na área de Cambissolo textura média fase floresta foi encontrado o maior volume de madeira para serraria, e o menor na área de Cambissolo textura média fase campo. Os sítios mais produtivos apresentaram maiores teores de $\mathrm{K} \mathrm{e} \mathrm{P,} \mathrm{pH} \mathrm{mais} \mathrm{elevado,} \mathrm{maior} \mathrm{saturação} \mathrm{por} \mathrm{bases} \mathrm{e} \mathrm{menor} \mathrm{saturação} \mathrm{por} \mathrm{Al.} \mathrm{Esses}$ mesmos sítios apresentaram menor porosidade total e macroporosidade, maior densidade do solo e maior teor de água disponível, que melhor se correlacionou com as variáveis de crescimento.

Palavras-chave: Classe de solo; vegetação original; textura do solo.
\end{abstract}

\begin{abstract}
Site influence on 22-years-old Pinus taeda growth: 1. Soil physico-hydrical and chemical characteristics. In order to evaluate the influence of site quality on pine tree growth, eight different sites were selected in a commercial Pinus taeda plantation belonging to Klabin, in Telêmaco Borba region, Parana State. Trees were 22 years old and sites were selected by soil type (Latosol and Cambisol), by soil texture (clayey and sandy) and by original vegetation (forest and grass). To characterize the sites, measurements of total height and DBH were taken from at least 50 trees at each site and soil samples were collected at three depths. Three average trees were selected from each site and DBH and total, sawing and cellulose heights were measured. The most important factor influencing tree growth, considering DBH increment, was the original vegetation phase. Original forest sites were the most productive of all. Cambissolo with loam texture and forest as original vegetation was the most productive site and the least productive site was a Cambissolo with loam texture and grass as original vegetation. The most productive site presented higher $\mathrm{P}$ and $\mathrm{K}$ contents, higher $\mathrm{pH}$, higher base saturation and lower $\mathrm{Al}$ saturation percentage. This site presented lower total and macro porosities, higher bulk density and higher amount of available soil water, which was highly correlated to the growth variables.

Keywords: Original vegetation; soil class; soil texture.
\end{abstract}

\section{INTRODUÇ̃̃̃}

Povoamentos florestais não apenas oferecem oportunidades para abastecer as demandas por lenha, celulose ou madeira serrada, como também reduzem os desmatamentos, por diminuir a pressão sobre as florestas, e ainda servem para recuperar solos degradados e garantir a biodiversidade 
(PAROTTA, 1992). Plantios florestais de ciclo rápido e alta produtividade demandam recursos naturais renováveis restritos a áreas menores, deixando mais espaço para outros tipos de florestas.

A produtividade dos plantios florestais precisa ser sustentável ou aumentada, devido aos altos investimentos iniciais de capital e recursos. As fábricas de papel e celulose e/ou serrarias são estabelecidas com a expectativa de obter matéria-prima suficiente originada de áreas próximas. Além dessas considerações econômicas e dos recursos, florestas plantadas devem ser exploradas sem causar impacto adverso ao meio ambiente (TIARKS et al., 1998).

A maioria dos solos tropicais é pobre em nutrientes, embora as florestas naturais não apresentem sintomas de deficiência, devido à ciclagem estar em perfeito equilíbrio com as demandas. A substituição de florestas naturais por plantios florestais de ciclo rápido altera os processos naturais de ciclagem $\mathrm{e}$ armazenamento de nutrientes, devido principalmente às mudanças causadas na qualidade da matéria orgânica pelas práticas de manejo. Isso dificulta a sustentabilidade do sítio, pelo importante papel da matéria orgânica nas propriedades químicas, físicas e biológicas do solo (NAMBIAR; BROWN, 1997).

Dentre os atributos do solo, o ambiente físico é o fator mais importante na produtividade do sítio, afetando propriedades do solo para a produção dos cultivos, que incluem os fluxos de água, ar e calor, a resistência do solo à penetração de raízes e a disponibilidade de nutrientes (LAL, 1979). Segundo Doldan (1990), os fatores físicos do solo, como a capacidade de retenção de água, a profundidade efetiva do horizonte A e o grau de desenvolvimento do perfil do solo, foram os que mais interferiram no crescimento de Pinus taeda. Snowdon; Benson (1992) verificaram que o fornecimento de água no solo aumentou o incremento anual em volume de madeira em Pinus radiata, e que a adubação isolada favoreceu apenas a biomassa da copa. Correia et al. (1996) também observaram em seus estudos que a disponibilidade de água foi essencial para o crescimento do Pinus taeda.

Como Pinus taeda é uma espécie considerada de baixa exigência nutricional, a ausência de sintomas de deficiência, particularmente nas primeiras rotações, condicionaram a idéia de que esta espécie dispensaria a prática da fertilização mineral (FERREIRA et al., 2001). Apesar de o gênero ser considerado pouco exigente quanto à fertilidade do solo, níveis diferenciados de produtividade têm sido observados quando se plantam espécies em condições edáficas distintas (BALLONI, 1984). Outros autores (MENEGOL, 1991; LASO GARICOITS, 1991) também estudaram os fatores do solo e as suas relações com o estado nutricional e a produtividade dessa espécie, demonstrando estreita interdependência entre essas variáveis. Bellote (2006), trabalhando também em diferentes sítios no Segundo Planalto do Paraná, relatou que alguns fatores do solo restringiram a possibilidade de se obterem toras acima de $24 \mathrm{~cm}$ de diâmetro por 2,20 $\mathrm{m}$ de altura, ou seja, nenhuma tora para uso em serraria, enquanto que, em área sem restrição de profundidade do solo e com plantas da mesma idade e espécie, obtiveram-se até cinco toras com as dimensões requeridas para a produção de madeira serrada.

A questão do emprego da fertilização mineral nos plantios de Pinus nas condições de solo e clima do Sul do Brasil não está ainda totalmente elucidada, e a parte referente à qualidade da madeira encontra-se em situação ainda menos adiantada. Devido ao rápido crescimento das espécies introduzidas, as características da madeira diferem daquelas obtidas com árvores crescendo no seu hábitat natural. Quanto dessas alterações é devido às características do sítio (solo e vegetação original), qual característica química e/ou física do solo condicionam o maior desenvolvimento das árvores de Pinus taeda e quais deveriam ser modificadas para melhorar o crescimento das árvores nos piores sítios foram os objetivos deste trabalho.

\section{MATERIAL E MÉTODOS}

As amostras de solo e de plantas foram obtidas em plantios comerciais de Pinus taeda estabelecidos em 1978, localizados em áreas da Klabin S.A., em Telêmaco Borba (PR), a 2408' latitude Sul e $50^{\circ} 30^{\prime}$ longitude Oeste, com altitude de 750 a $868 \mathrm{~m}$.

O clima da região, segundo a classificação de Köppen, é Cfa/Cfb, subtropical úmido transicional, para temperado propriamente dito, em que a temperatura média do mês mais frio é inferior a $16^{\circ} \mathrm{C}$, com ocorrência de geada, e a temperatura média do mês mais quente é superior a $22^{\circ} \mathrm{C}$. A precipitação média anual é $1490 \mathrm{~mm}$, com excedente hídrico de $557 \mathrm{~mm} / \mathrm{ano}$, distribuído em todos os meses do ano (EMBRAPA, 1984).

$\mathrm{O}$ material de origem da região é predominantemente resultante do intemperismo e 
retrabalhamento de litologias referentes às formações Rio Bonito, Itararé e Diques de Diabásio (EMBRAPA, 1984).

A cobertura vegetal primitiva era representada pelo contato estepe/floresta, sendo $51 \%$ formação florestal e 49\% formação campo (EMBRAPA, 1984).

Os sítios foram selecionados pela vegetação original (campo e floresta), pela classe de solo (Latossolo e Cambissolo) e pela textura (argilosa/muito argilosa e média). Os dados da análise granulométrica são apresentados na tabela 1 .

Tabela 1. Resultados da análise granulométrica dos solos dos sítios selecionados, na profundidade de 0 a $20 \mathrm{~cm}$. Table 1. Results of particle distribution analyses from soils of selected sites, at 0 to $20 \mathrm{~cm}$ soil layer.

\begin{tabular}{lcccccc}
\hline \multirow{2}{*}{ Solo } & \multirow{2}{*}{ Textura } & \multirow{2}{*}{ Vegetação original } & Areia grossa & Areia fina & Silte & Argila \\
\cline { 3 - 7 } & & & & $\%$ & & \\
\hline Cambissolo & argilosa & floresta & 3 & 4 & 32 & 61 \\
Latossolo & argilosa & floresta & 9 & 19 & 26 & 46 \\
Cambissolo & média & floresta & 19 & 31 & 34 & 16 \\
Latossolo & argilosa & campo & 6 & 21 & 13 & 60 \\
Cambissolo & argilosa & campo & 14 & 20 & 20 & 46 \\
Latossolo & média & floresta & 19 & 41 & 15 & 25 \\
Latossolo & média & campo & 21 & 42 & 10 & 27 \\
Cambissolo & média & campo & 21 & 44 & 15 & 20 \\
\hline
\end{tabular}

Para a caracterização dos sítios, foram realizadas avaliações dendrométricas de 50 árvores por sítio e selecionaram-se 3 árvores médias (altura e DAP) por sítio, nas quais foram medidas altura total, altura para serraria (diâmetro mínimo de $24 \mathrm{~cm}$ ) e para celulose (diâmetro mínimo de $8 \mathrm{~cm}$ ) e DAP. O volume de madeira para serraria foi estimado usando-se o diâmetro médio entre o diâmetro da base e 24 $\mathrm{cm}$. Foram coletadas também amostras de solo indeformadas e a granel a $50 \mathrm{~cm}$ de cada árvore derrubada e em 3 profundidades: 0 a 10, 10 a 20 e 20 a $30 \mathrm{~cm}$. Nessas amostras de solo, foram feitas análises químicas (macroelementos, CTC e matéria orgânica) e físico-hídricas (densidade, condutividade saturada, disponibilidade de água e profundidade efetiva), seguindo-se metodologia descrita em Embrapa (1997).

Os resultados dos atributos estudados foram submetidos à análise de variância e ao teste de Tukey. Foram utilizados o modelo de regressão linear simples e os coeficientes de correlação para entendimento das relações existentes entre as variáveis estudadas.

\section{RESULTADOS E DISCUSSÃO}

Os sítios na tabela 2 foram classificados pelo volume para serraria, que foi a característica principal para os objetivos propostos. Essa classificação seria diferente se fosse obtida pela altura para serraria. A capacidade produtiva de um sítio florestal pode ser avaliada, para determinado local, através da medição de fatores intrínsecos ou extrínsecos à biomassa florestal. Ortega e Monteiro (1973) destacam, como fatores intrínsecos, a altura dominante ou média, o crescimento médio máximo e o volume total no final da rotação.

Em termos de altura para serraria, os quatro primeiros sítios não diferem entre si, situando-se essas diferenças ao redor de $2 \mathrm{~m}$, entre o sítio mais produtivo e o quarto (Tabela 2). Já entre o sítio com maior altura - Cambissolo textura argilosa fase floresta nativa - e o sítio com menor altura - Cambissolo textura média fase campo nativo -, essa diferença é de aproximadamente 8,6 m, que equivale a um crescimento menor do sítio menos produtivo de $85 \%$.

Uma vez que o espaçamento usado em todos os sítios selecionados foi de $2,5 \times 2,5 \mathrm{~m}$ e a condução, desbastes e podas foram semelhantes, em se considerando o DAP, o sítio mais produtivo seria o Cambissolo textura média fase floresta. Nesse caso não houve alteração da classe de solo e da vegetação original para o sítio mais produtivo, apenas da classe textural do solo. Esse sítio mais produtivo diferenciou-se dos demais, sendo a diferença para o segundo melhor sítio em DAP de apenas 2,5 cm, o que equivale a $5 \%$. Provavelmente, essa diferença tenha sido altamente significativa devido ao coeficiente de variação ser bastante baixo (Tabela 2). No entanto, em se comparando os DAPs dos sítios com maior $(43,7 \mathrm{~cm})$ e menor $(34,3 \mathrm{~cm})$ crescimento, essa diferença é de $9,4 \mathrm{~cm}$, que equivale a $30 \%$ a menos de 
DAP para as árvores do sítio menos produtivo - Cambissolo textura média fase campo nativo.

Tabela 2. DAP, altura total, altura para serraria e para celulose das árvores de Pinus taeda com 22 anos de idade por sítio.

Table 2. DBH, total, saw and cellulose heights from Pinus taeda trees at 22 years of age for every site.

\begin{tabular}{|c|c|c|c|c|c|c|c|}
\hline \multirow{2}{*}{ Solo } & \multirow{2}{*}{ Textura } & \multirow{2}{*}{$\begin{array}{l}\text { Vegetação } \\
\text { Original }\end{array}$} & \multirow{2}{*}{$\begin{array}{l}\text { DAP } \\
(\mathbf{c m})\end{array}$} & \multicolumn{3}{|c|}{ Altura (m) } & \multirow{2}{*}{$\begin{array}{c}\text { Volume } \\
\text { p/serraria } \\
\text { (m³/árvore) }\end{array}$} \\
\hline & & & & Total & Serraria & Celulose & \\
\hline Cambissolo & média & floresta & $43,7 \mathrm{a}$ & $26,2 b$ & $18,2 \mathrm{a}$ & $23,7 \mathrm{ab}$ & $1,38 \mathrm{a}$ \\
\hline Latossolo & argilosa & floresta & $41,2 b$ & $27,4 \mathrm{ab}$ & $18,4 \mathrm{a}$ & $23,9 \mathrm{ab}$ & $1,25 \mathrm{ab}$ \\
\hline Cambissolo & argilosa & floresta & $38,3 \mathrm{c}$ & $30,4 \mathrm{a}$ & $19,0 \mathrm{a}$ & $27,0 \mathrm{a}$ & $1,10 \mathrm{abc}$ \\
\hline Latossolo & argilosa & campo & $38,0 \mathrm{c}$ & $29,4 \mathrm{ab}$ & $17,4 \mathrm{a}$ & $25,6 \mathrm{ab}$ & $0,98 \mathrm{bc}$ \\
\hline Cambissolo & argilosa & campo & $37,3 \mathrm{~cd}$ & $26,2 \mathrm{~b}$ & $15,3 \mathrm{ab}$ & $22,3 b$ & $0,83 \mathrm{~cd}$ \\
\hline Latossolo & média & floresta & $35,3 \mathrm{~d}$ & $21,7 \mathrm{c}$ & $12,4 b c$ & $18,5 \mathrm{c}$ & $0,59 \mathrm{de}$ \\
\hline Latossolo & média & campo & $35,0 \mathrm{~d}$ & $21,9 \mathrm{c}$ & $11,8 \mathrm{bc}$ & $18,6 \mathrm{c}$ & $0,59 \mathrm{de}$ \\
\hline Cambissolo & média & campo & $34,3 \mathrm{~d}$ & $20,2 \mathrm{c}$ & $10,4 \mathrm{c}$ & $17,1 \mathrm{c}$ & $0,47 \mathrm{e}$ \\
\hline \multicolumn{3}{|c|}{ Coeficiente de Variação (\%) } & 1,9 & 4,7 & 8,8 & 5,5 & 12,4 \\
\hline
\end{tabular}

Médias seguidas por letras distintas diferem entre si ao nível de significância de $5 \%$ pelo teste de Tukey.

Quando se analisa separadamente a contribuição de cada uma das três características dos oito sítios estudados (tipo de solo, textura do solo e vegetação original) e as suas interações, é possível avaliar a contribuição de cada uma (Tabela 3). A textura foi a característica que alcançou os maiores valores pelo teste de F para as alturas das árvores e também a única característica que apresentou diferenças significativas para todas as variáveis analisadas (Tabela 3). A característica vegetação original apresentou valores maiores de F para as variáveis dendrométricas DAP e volume para serraria, e o tipo de solo apresentou diferença significativa apenas para a variável DAP. Para essa mesma variável, todas as características apresentaram-se significativamente diferentes, inclusive suas interações, possivelmente porque a diferença entre o valor máximo e o mínimo foi de $10,5 \mathrm{~cm}(20 \%$ do maior valor).

Já para as alturas, a textura foi a característica mais importante. Os sítios com solos argilosos proporcionaram os maiores valores em todas as alturas obtidas neste estudo, sendo a altura uma das variáveis mais usadas na avaliação da produtividade dos sítios. Segundo Zobel et al. (1987), os solos argilosos costumam ser naturalmente mais férteis que os arenosos, embora possam apresentar drenagem insuficiente. Rigatto et al. (2004), trabalhando com Pinus taeda aos oito anos de idade, concluíram que os solos de textura argilosa propiciaram maior crescimento dessa espécie, independentemente da classe do solo a que pertencem.

Para todas as variáveis dendrometrias, o Cambissolo foi mais produtivo que o Latossolo, solos de textura argilosa foram superiores aos de textura média e solos de vegetação original floresta possibilitaram maior crescimento. Naturalmente, uma cobertura vegetal com floresta ocorre em solos mais profundos, mais férteis e com regime hídrico apropriado, devido à maior biomassa nesse tipo de cobertura vegetal quando comparado à do campo nativo, além de os Cambissolos serem em geral solos menos intemperizados e com presença de alguns minerais primários (EMBRAPA, 1984).

As tabelas 4 e 5 seguem a seqüência apresentada na tabela 2, na qual os sítios estão classificados pelo volume de produção de madeira para serraria, buscando-se facilitar o estabelecimento de correlações dessa variável de produção com as características físicas e químicas do solo e do estado nutricional das plantas.

Observa-se na tabela 4 que, das cinco características físico-hídricas do solo dos oito sítios apresentados, apenas o teor de água disponível não mostrou diferenças significativas, muito provavelmente devido ao alto valor do coeficiente de variação para essa variável, contudo, considerandose diferenças de valores de até $100 \%$ para essa característica, serão apresentadas discussões baseadas nos valores numéricos encontrados. Deve-se salientar que as classes de solo estudadas diferem muito pouco entre si no que se refere à profundidade efetiva do solo, uma das características apontadas como principais fatores de redução da produtividade do gênero Pinus (CARVALHO et al., 1999). Têm em comum ainda, as classes Latossolo e Cambissolo, uma estrutura porosa sem camadas naturais de impedimento, boa drenagem interna da água da chuva e pouca restrição à mecanização (EMBRAPA, 1984). 
Tabela 3. Valores do teste de $\mathrm{F}$ e níveis de significância para estes valores, quando se separam as variáveis que compõem os diferentes sítios estudados.

Table 3. Values of $\mathrm{F}$ test and level of significance for these values, when variables from different sites were analyzed separately.

\begin{tabular}{|c|c|c|c|c|c|c|}
\hline \multirow{2}{*}{$\begin{array}{c}\text { Fontes de } \\
\text { variação }\end{array}$} & \multirow{2}{*}{$\begin{array}{l}\text { Graus de } \\
\text { liberdade }\end{array}$} & \multicolumn{3}{|c|}{ Altura } & \multirow{2}{*}{ DAP } & \multirow{2}{*}{$\begin{array}{l}\text { Volume } \\
\text { Serraria }\end{array}$} \\
\hline & & Total & Serraria & Celulose & & \\
\hline \multicolumn{7}{|c|}{ Valores de F e níveis de significância } \\
\hline Solo & 1 & $1,67 \mathrm{~ns}$ & $1,83 \mathrm{~ns}$ & $0,32 \mathrm{~ns}$ & $13,02 * *$ & $4,27 \mathrm{~ns}$ \\
\hline Textura & 1 & $142,43 * *$ & $60,61 * *$ & $6,86^{*}$ & $31,69 * *$ & $39,06 * *$ \\
\hline Vegetação & 1 & $16,65 * *$ & $34,71 * *$ & $1,02 \mathrm{~ns}$ & $143,52 * *$ & $63,26 * *$ \\
\hline $\mathrm{S} * \mathrm{~T}$ & 1 & $2,14 \mathrm{~ns}$ & $7,32 *$ & $0,32 \mathrm{~ns}$ & $93,52 * *$ & $28,23 * *$ \\
\hline $\mathrm{S} * \mathrm{~V}$ & 1 & $39,99 * *$ & $20,06 * *$ & $2,62 \mathrm{~ns}$ & $35,02 * *$ & $24,94 * *$ \\
\hline $\mathrm{T}^{*} \mathrm{~V}$ & 1 & $3,25 \mathrm{~ns}$ & $2,73 \mathrm{~ns}$ & $0,12 \mathrm{~ns}$ & $22,69 * *$ & $4,35 \mathrm{~ns}$ \\
\hline $\mathrm{S} * \mathrm{~T} * \mathrm{~V}$ & 1 & $0,00 \mathrm{~ns}$ & $3,94 \mathrm{~ns}$ & $0,00 \mathrm{~ns}$ & $93,52 * *$ & $25,72 * *$ \\
\hline Resíduo & 14 & & & & & \\
\hline TOTAL & 23 & & & & & \\
\hline
\end{tabular}

Constata-se, na tabela 4, que os dois Cambissolos com árvores com a maior altura média para serraria e maior DAP médio mostraram valores das características físico-hídricas menores na camada superficial do solo de 0 a $10 \mathrm{~cm}$, ou seja, maior densidade global, menores porosidades total e macro. No entanto, apresentaram os maiores teores de água disponível e de umidade atual, que é o teor de umidade no momento da amostragem. Isso mostra que, para esses solos, desde que limites críticos não sejam atingidos (como macroporosidade inferior a $0,10 \mathrm{~cm}^{3} \cdot \mathrm{cm}^{-3}$ ), uma maior microporosidade pode ser benéfica para 0 crescimento de Pinus taeda. Segundo Doldan (1990), os fatores físicos do solo, como a capacidade de retenção de água, a profundidade efetiva do horizonte A e o grau de desenvolvimento do perfil do solo, foram os que mais interferiram no crescimento de Pinus taeda. Snowdon e Benson (1992) verificaram que o fornecimento de água no solo aumentou o incremento anual em volume de madeira em Pinus radiata e que a adubação isolada favoreceu apenas a biomassa da copa. Correia et al. (1996) também observaram em seus estudos que a disponibilidade de água foi essencial para o crescimento de Pinus taeda.

O Cambissolo textura argilosa fase floresta e o Cambissolo textura média fase floresta apresentaram microporosidades de 74 e $77 \%$, respectivamente, na camada de 0 a $10 \mathrm{~cm}$ de profundidade, enquanto o solo com menor crescimento médio das árvores, o Cambissolo textura média fase campo, apresentou uma microporosidade de 54\%. A ocorrência de maior umidade na camada superficial, camada normalmente mais rica em nutrientes pelo maior teor de matéria orgânica e ciclagem da serapilheira, pode ter contribuído decisivamente para o maior crescimento das árvores nos sítios mais produtivos. Segundo Reissmann e Wisniewski (2000), em situações em que a oferta de água no solo é maior, a disponibilidade de potássio aumenta, visto que o teor de água no solo é essencial para a movimentação e absorção desse elemento. O teor de água disponível no solo do sítio com árvores de maior altura média para serraria e do sítio com árvores com maior DAP são os maiores entre os sítios estudados. Esses valores podem parecer baixos, mas comparativamente aos demais sítios podem representar $100 \%$ a mais de água disponível na camada superficial do solo, apesar da não diferenciação estatística entre os tratamentos. Na camada de solo de 10 a $20 \mathrm{~cm}$, observa-se uma redução generalizada da macroporosidade de todos os sítios, chegando a menos de $10 \%$ no Cambissolo textura média fase floresta, o que resultou em um aumento do teor de água disponível nesses solos. Os dois sítios com maior teor de água disponível são também os que apresentam maior teor de silte (Tabela 1), característica que sempre resulta em maior disponibilidade de água no solo (HILLEL, 1980). A maior microporosidade conferida ao solo pelo silte aumenta a força de retenção de água pela capilaridade, e a força de retenção da água pela matriz desse solo é bem menor quando comparada à exercida por um solo argiloso (HILLEL, 1980). O Cambissolo textura média fase floresta com maior volume de madeira para serraria e maior teor de água disponível apresenta, além de altos teores da fração silte, alta percentagem de areia fina na sua distribuição granulométrica. Essa dominância das frações areia fina e silte confere a esse solo maior disponibilidade de água (HILLEL, 1980), razão pela qual ele aparece, na classificação dos sítios por volume para serraria, melhor do que os solos argilosos. 
Tabela 4. Características físico-hídricas do solo dos oito sítios em três profundidades, listados em ordem decrescente para volume de árvores para serraria.

Table 4. Soil physical characteristics for eight sites at three different depths, classified in descendent order by tree volume of wood.

\begin{tabular}{|c|c|c|c|c|c|c|c|}
\hline \multirow{3}{*}{ Solo } & \multirow{3}{*}{ Textura } & \multirow{3}{*}{$\begin{array}{c}\text { Vegetação } \\
\text { original }\end{array}$} & \multirow{3}{*}{$\begin{array}{c}\text { Densidade do } \\
\text { solo } \\
\mathrm{kg} \mathrm{dm}^{-3}\end{array}$} & \multicolumn{2}{|c|}{ Porosidade } & \multirow{2}{*}{$\begin{array}{c}\text { Umidade } \\
\text { atual }\end{array}$} & \multirow{2}{*}{$\begin{array}{c}\text { Água } \\
\text { disponível }\end{array}$} \\
\hline & & & & total & macro & & \\
\hline & & & & \multicolumn{4}{|c|}{$\mathrm{cm}^{3} \mathrm{~cm}^{-3}$} \\
\hline \multicolumn{3}{|c|}{ Profundidade $(\mathrm{cm})$} & & & 0 a 10 & & \\
\hline Cambis & média & floresta & $1,308 \mathrm{c}$ & $0,508 \mathrm{e}$ & $0,117 \mathrm{c}$ & $0,288 b$ & $0,040 \mathrm{a}$ \\
\hline Latos & argilosa & floresta & $1,087 \mathrm{abc}$ & $0,601 b c$ & $0,196 \mathrm{bc}$ & $0,333 \mathrm{a}$ & $0,024 \mathrm{a}$ \\
\hline Cambis & argilosa & floresta & $1,293 \mathrm{c}$ & $0,518 \mathrm{de}$ & $0,133 \mathrm{c}$ & $0,341 \mathrm{a}$ & $0,032 \mathrm{a}$ \\
\hline Latos & argilosa & campo & $1,200 \mathrm{c}$ & $0,631 \mathrm{abc}$ & $0,163 \mathrm{c}$ & $0,328 \mathrm{ab}$ & $0,019 \mathrm{a}$ \\
\hline Cambis & argilosa & campo & $1,136 \mathrm{c}$ & $0,594 \mathrm{~cd}$ & $0,153 \mathrm{c}$ & $0,332 \mathrm{a}$ & $0,026 \mathrm{a}$ \\
\hline Latos & média & floresta & $0,914 \mathrm{ab}$ & $0,687 \mathrm{a}$ & $0,168 \mathrm{c}$ & $0,352 \mathrm{a}$ & $0,026 \mathrm{a}$ \\
\hline Latos & média & campo & $0,896 \mathrm{a}$ & $0,674 \mathrm{ab}$ & $0,386 \mathrm{a}$ & $0,149 \mathrm{c}$ & $0,027 \mathrm{a}$ \\
\hline Cambis & média & campo & $1,162 \mathrm{c}$ & $0,582 \mathrm{cde}$ & $0,266 \mathrm{~b}$ & $0,117 \mathrm{c}$ & $0,021 \mathrm{a}$ \\
\hline \multicolumn{3}{|c|}{ Coeficiente de variação (\%) } & 9,5 & 6,2 & 19,9 & 6,8 & 38,5 \\
\hline \multicolumn{3}{|c|}{ Profundidade $(\mathrm{cm})$} & & & 10 a 20 & & \\
\hline Cambis & média & floresta & $1,421 \mathrm{e}$ & $0,444 \mathrm{c}$ & $0,080 \mathrm{~d}$ & $0,296 \mathrm{c}$ & $0,038 \mathrm{a}$ \\
\hline Latos & argilosa & floresta & $1,175 \mathrm{bc}$ & $0,556 \mathrm{~b}$ & $0,122 \mathrm{~cd}$ & $0,354 \mathrm{ab}$ & $0,035 \mathrm{a}$ \\
\hline Cambis & argilosa & floresta & $1,484 \mathrm{e}$ & $0,444 \mathrm{c}$ & $0,112 \mathrm{~cd}$ & $0,293 \mathrm{c}$ & $0,030 \mathrm{a}$ \\
\hline Latos & argilosa & campo & $1,092 \mathrm{abc}$ & $0,652 \mathrm{a}$ & $0,231 b$ & 0,311 & $0,033 \mathrm{a}$ \\
\hline Cambis & argilosa & campo & $1,219 \mathrm{bcd}$ & $0,558 \mathrm{~b}$ & $0,103 d$ & $0,327 \mathrm{bc}$ & $0,036 \mathrm{a}$ \\
\hline Latos & média & floresta & $1,035 \mathrm{ab}$ & $0,647 \mathrm{a}$ & $0,158 \mathrm{c}$ & $0,380 \mathrm{a}$ & $0,023 \mathrm{a}$ \\
\hline Latos & média & campo & $0,935 \mathrm{a}$ & $0,664 \mathrm{a}$ & $0,371 \mathrm{a}$ & $0,181 \mathrm{e}$ & $0,021 \mathrm{a}$ \\
\hline Cambis & média & campo & $1,380 \mathrm{de}$ & $0,484 \mathrm{~b}$ & $0,176 b c$ & $0,138 \mathrm{e}$ & $0,034 \mathrm{a}$ \\
\hline \multicolumn{3}{|c|}{ Coeficiente de variação (\%) } & 6,4 & 3,5 & 20,0 & 6,8 & 54,5 \\
\hline \multicolumn{3}{|c|}{ Profundidade $(\mathrm{cm})$} & & & 20 a 30 & & \\
\hline Cambis & média & floresta & $1,384 \mathrm{c}$ & $0,518 \mathrm{de}$ & $0,111 \mathrm{de}$ & $0,296 \mathrm{bcd}$ & $0,020 \mathrm{a}$ \\
\hline Latos & argilosa & floresta & $1,181 \mathrm{~b}$ & $0,530 \mathrm{~d}$ & $0,116 \mathrm{cde}$ & $0,326 b c$ & $0,024 \mathrm{a}$ \\
\hline Cambis & argilosa & floresta & $1,514 \mathrm{~d}$ & $0,401 \mathrm{f}$ & $0,081 \mathrm{e}$ & $0,278 \mathrm{~d}$ & $0,035 \mathrm{a}$ \\
\hline Latos & argilosa & campo & $1,144 \mathrm{ab}$ & $0,633 a b$ & $0,199 \mathrm{ab}$ & $0,332 b$ & $0,029 \mathrm{a}$ \\
\hline Cambis & argilosa & campo & $1,164 \mathrm{~b}$ & $0,584 \mathrm{c}$ & $0,155 \mathrm{bcd}$ & $0,289 \mathrm{~cd}$ & $0,031 \mathrm{a}$ \\
\hline Latos & média & floresta & $1,022 \mathrm{a}$ & $0,675 \mathrm{a}$ & $0,162 b c$ & $0,389 \mathrm{a}$ & $0,022 \mathrm{a}$ \\
\hline Latos & média & campo & $1,188 \mathrm{~b}$ & $0,616 b c$ & $0,235 \mathrm{a}$ & $0,258 \mathrm{~d}$ & $0,015 \mathrm{a}$ \\
\hline Cambis & média & campo & $1,452 \mathrm{~cd}$ & $0,484 \mathrm{e}$ & $0,173 b$ & $0,162 \mathrm{e}$ & $0,022 \mathrm{a}$ \\
\hline \multicolumn{3}{|c|}{ Coeficiente de variação, \% } & 4,9 & 3,7 & 14,6 & 6,7 & 36,2 \\
\hline
\end{tabular}

Pelos pequenos valores dos coeficientes de variação observados na tabela 4 para a maioria das características físico-hídricas, pode-se concluir que a área de amostragem foi muito uniforme dentro de cada sítio avaliado. Assim, para as características químicas do solo (Tabela 5), não foram realizadas as análises estatísticas, uma vez que foi coletada apenas uma amostra de solo composta por sítio, porque as árvores selecionadas eram sempre muito próximas e nesses plantios não foram feitas adubações. $\mathrm{Na}$ tabela 5, os maiores valores de cada característica química do solo, para cada camada, encontram-se em negrito, para facilitar a visualização da coincidência ou não destes com os sítios mais produtivos.

Observa-se na tabela 5 que, na camada de 0 a $10 \mathrm{~cm}$, das sete variáveis químicas apresentadas, $o$ sítio com maior média de altura (Cambissolo textura argilosa fase floresta) apresentou melhores valores em cinco delas, maiores $\mathrm{pH}$ e teores de $\mathrm{K}$ e P, maior saturação por bases e menor saturação por Al. Nas outras duas características, teores de $\mathrm{Ca}+\mathrm{Mg}$ e de matéria orgânica, seus valores são muito próximos ao do solo do sítio com maiores valores. Segundo Haag (1983), os maiores incrementos em volume de madeira foram obtidos com a elevação do $\mathrm{pH}$ do solo e a aplicação de fósforo e potássio. Para Laso Garicoits (1990), o crescimento do Pinus taeda, na mesma região deste estudo, foi prejudicado pela baixa 
disponibilidade de $\mathrm{P}, \mathrm{K}, \mathrm{Mg}$ e $\mathrm{Zn}$ no solo, sendo que o $\mathrm{K}$ e o $\mathrm{Zn}$ foram os nutrientes mais limitantes. Apenas o teor de $\mathrm{K}$ no Cambissolo textura argilosa fase floresta pode ser classificado como médio (TOMÉ JR., 1997), e é bastante superior ao dos demais solos tidos como baixos, quatro a cinco vezes maior que a maioria dos outros solos deste estudo, na camada de 0 a $10 \mathrm{~cm}$. Essa diferença de teor de $\mathrm{K}$ no solo, entre esse sítio e os demais, permanece nas camadas de 10 a $20 \mathrm{~cm}$ e de 20 a $30 \mathrm{~cm}$, onde os valores de todos podem ser classificados como baixos (TOMÉ JR., 1997).

$\mathrm{O}$ mesmo ocorreu com o $\mathrm{P}$ e a saturação por bases, que foi aproximadamente o dobro da apresentada pelos demais solos, em todas as camadas de solo amostradas. Respostas positivas foram obtidas em Pinus taeda de sete anos de idade com aplicação de P (MUNIZ et al., 1975). Também Cromer et al. (1985) apontaram P como o mais limitante para a produção de Pinus taeda. Os níveis de P nos solos da maioria dos sítios podem ser classificados como médios a altos, sendo que no Cambissolo textura média fase floresta ele é muito alto (TOMÉ JR., 1997) na camada de 10 a $20 \mathrm{~cm}$. No entanto, pode-se observar que o sítio com o menor volume de madeira para serraria (Cambissolo textura média fase floresta) também apresenta valores elevados de $\mathrm{P}$, que como fator isolado não lhe garantiu um bom desenvolvimento.

Segundo Bartz et al. (1995), os teores de Ca $+\mathrm{Mg}$ são muito baixos para os solos de todos os sítios e em todas as camadas amostradas (Tabela 5). O mesmo acontece para os valores de $\mathrm{pH}$ e exatamente o oposto ocorreu com os valores de saturação por Al, que são muito altos até para uma espécie como P. taeda, considerada como tolerante.

Tabela 5. Características químicas dos solos dos oito sítios classificados em ordem decrescente para volume de árvores para serraria, em três profundidades.

Table 5. Soil chemical characteristics for eight sites classified in descendent order by tree volume of wood, at three depths.

\begin{tabular}{|c|c|c|c|c|c|c|c|c|c|}
\hline Solo & Textura & $\begin{array}{l}\text { Veget. } \\
\text { Original }\end{array}$ & $\begin{array}{c}\mathrm{pH} \\
\mathrm{CaCl}_{2} \\
\end{array}$ & $\mathbf{K}$ & $\frac{\mathrm{Ca}+\mathrm{Mg}}{\mathrm{ol}_{\mathbf{c}} \cdot \mathrm{dm}^{-3}}$ & $\begin{array}{c}\text { Satur. } \\
\text { bases } \\
\%\end{array}$ & $\underset{\text { mg.dm }^{-3}}{P}$ & $\begin{array}{c}\text { Matéria } \\
\text { orgânica } \\
\mathbf{g ~ k g}^{-1}\end{array}$ & $\begin{array}{c}\text { Saturação } \\
\text { por Al } \\
\%\end{array}$ \\
\hline \multicolumn{3}{|c|}{ Profundidade $(\mathrm{cm})$} & \multicolumn{7}{|c|}{0 a 10} \\
\hline Cambis & média & floresta & 3,45 & 0,06 & 0,47 & 6,3 & 5,6 & 9,3 & 79,9 \\
\hline Latos & argilosa & floresta & 3,41 & 0,05 & 0,66 & 5,2 & 4,9 & 8,3 & 78,9 \\
\hline Cambis & argilosa & floresta & 3,80 & $\mathbf{0 , 2 0}$ & 0,64 & 11,9 & 8,9 & 19,2 & 64,0 \\
\hline Latos & argilosa & campo & 3,44 & 0,06 & 0,46 & 3,9 & 4,8 & 10,0 & 79,8 \\
\hline Cambis & argilosa & campo & 3,22 & 0,03 & 0,40 & 3,9 & 4,6 & 21,1 & 80,8 \\
\hline Latos & média & floresta & 3,51 & 0,03 & 0,50 & 5,5 & 4,9 & 18,9 & 71,3 \\
\hline Latos & média & campo & 3,50 & 0,15 & 0,48 & 6,0 & 5,6 & 5,8 & 78,9 \\
\hline Cambis & média & campo & 3,31 & 0,07 & 0,40 & 3,9 & 7,3 & 18,3 & 86,3 \\
\hline \multicolumn{3}{|c|}{ Profundidade, $\mathrm{cm}$} & \multicolumn{7}{|c|}{10 a 20} \\
\hline Cambis & média & floresta & 3,57 & 0,04 & 0,38 & 8,5 & 6,4 & 6,5 & 81,5 \\
\hline Latos & argilosa & floresta & 3,50 & 0,04 & 0,49 & 11,0 & 5,2 & 8,1 & 74,8 \\
\hline Cambis & argilosa & floresta & 3,61 & 0,12 & 0,43 & 8,0 & 6,8 & 18,5 & 78,8 \\
\hline Latos & argilosa & campo & 3,50 & 0,03 & 0,40 & 7,6 & 4,6 & 8,5 & 82,9 \\
\hline Cambis & argilosa & campo & 3,57 & 0,01 & 0,35 & 5,0 & 4,4 & 21,0 & 72,7 \\
\hline Latos & média & floresta & 3,52 & 0,03 & 0,46 & 8,9 & 4,5 & 16,3 & 72,4 \\
\hline Latos & média & campo & 3,55 & $\mathbf{0 , 1 3}$ & 0,39 & 10,6 & 5,5 & 5,0 & 78,4 \\
\hline Cambis & média & campo & 3,50 & 0,05 & 0,40 & 9,8 & 7,3 & 5,3 & 82,8 \\
\hline \multicolumn{3}{|c|}{ Profundidade $(\mathrm{cm})$} & \multicolumn{7}{|c|}{20 a 30} \\
\hline Cambis & média & floresta & 3,57 & 0,03 & 0,41 & 8,5 & 1,6 & 6,4 & 79,9 \\
\hline Latos & argilosa & floresta & 3,50 & 0,06 & 0,48 & 11,8 & 1,4 & 6,1 & 81,1 \\
\hline Cambis & argilosa & floresta & 3,54 & $\mathbf{0 , 0 7}$ & 0,47 & 6,1 & 6,3 & 2,8 & 80,5 \\
\hline Latos & argilosa & campo & 3,57 & 0,03 & 0,40 & 6,6 & 5,9 & 7,0 & 82,4 \\
\hline Cambis & argilosa & campo & 3,67 & 0,01 & 0,30 & 4,3 & 2,2 & 8,3 & 64,1 \\
\hline Latos & média & floresta & 3,58 & 0,03 & 0,38 & 7,4 & 1,6 & 10,0 & 75,0 \\
\hline Latos & média & campo & 3,47 & $\mathbf{0 , 0 7}$ & 0,45 & 11,4 & 2,6 & 4,6 & 66,7 \\
\hline Cambis & média & campo & 3,56 & 0,03 & 0,34 & 8,4 & 4,6 & 5,2 & 87,4 \\
\hline
\end{tabular}


Poucas correlações entre as variáveis de crescimento de Pinus taeda e as características físicohídricas e químicas do solo foram expressivas a ponto de contribuir em mais de $50 \%$ para a variação observada no desenvolvimento das plantas nos diferentes sítios estudados (Tabela 6). Dentre as características físicas do solo, destaca-se a importância do teor de água disponível na camada de 20 a 30 $\mathrm{cm}$ com a altura total. É importante observar que, para essas variáveis, as correlações com as porosidades são negativas e positivas com a densidade dos solos, mostrando que para as classes de solo estudadas um aumento da microporosidade seria desejável. Essas correlações podem estar sendo negativas porque são características observadas em solos de textura média a arenosa e, como pode ser observado na tabela 2 , estes foram os solos com menor crescimento do Pinus taeda. Para as principais variáveis das plantas medidas, a textura apresentou valores de F com probabilidade elevada (Tabela 3), mostrando ser um fator de sítio importante. Já com as características químicas do solo, a correlação delas com as variáveis de crescimento, embora não significativas, foram na direção esperada, também observada por Rigatto et al. (2004) para P. taeda com oito anos de idade.

Tabela 6. Coeficientes de correlação entre as variáveis de crescimento do Pinus taeda e características físico-hídricas e químicas do solo.

Table 6. Correlation coefficients among Pinus taeda growth variables and soil physical and chemical characteristics.

\begin{tabular}{|c|c|c|c|c|c|c|}
\hline \multirow{2}{*}{$\begin{array}{l}\text { Variável do solo } \\
\text { Caract. físico-hídricas }\end{array}$} & \multirow{2}{*}{$\begin{array}{c}\text { Profundidade } \\
(\mathrm{cm})\end{array}$} & \multicolumn{3}{|c|}{ Altura } & \multirow{2}{*}{ DAP } & \multirow{2}{*}{$\begin{array}{c}\text { Volume } \\
\text { p/serraria }\end{array}$} \\
\hline & & Total & Serraria & Celulose & & \\
\hline Umidade atual & 0 a 10 & 0,69 & 0,70 & 0,68 & & \\
\hline Porosidade total & 0 a 10 & & $-0,61$ & & $-0,64$ & $-0,66$ \\
\hline \multirow[t]{2}{*}{ Macroporosidade } & 0 a 10 & $-0,63$ & $-0,69$ & $-0,66$ & & $-0,63$ \\
\hline & 20 a 30 & $-0,68$ & & & $-0,64$ & $-0,68$ \\
\hline \multirow[t]{3}{*}{ Água disponível } & 0 a 10 & & & & 0,64 & \\
\hline & 10 a 20 & & & & 0,65 & 0,61 \\
\hline & 20 a 30 & 0,74 & & 0,70 & & \\
\hline Densidade solo & 0 a 10 & 0,64 & 0,66 & 0,68 & & 0,65 \\
\hline Areia grossa & 0 a 10 & $-0,65$ & $-0,72$ & $-0,67$ & $-0,54$ & \\
\hline Caract. químicas & $\mathrm{cm}$ & & & $\mathrm{r}$ & & \\
\hline \multirow[t]{2}{*}{$\mathrm{Ca}+\mathrm{Mg}$} & 0 a 10 & 0,68 & & 0,67 & & \\
\hline & 20 a 30 & 0,63 & & 0,64 & & \\
\hline$P$ & 20 a 30 & & 0,61 & & 0,69 & 0,66 \\
\hline
\end{tabular}

\section{CONCLUSÕES}

- A fase de vegetação original (floresta), seguida pela textura (argilosa) foram as principais características dos sítios estudados que influenciam nas variáveis de crescimento do Pinus taeda para serraria, aos 22 anos de idade.

- A altura das plantas foi mais influenciada pela textura do solo, sendo que em solos de textura argilosa as alturas são maiores do que em solos de textura média.

- Apenas os valores de DAP apresentam diferenças significativas, considerando-se as classes de solo, Cambissolo e Latossolo.

- O solo do sítio mais produtivo apresentou menores porosidade total e macroporosidade, maior densidade do solo e maior teor de água disponível, sendo que esta última variável apresentou a maior correlação positiva com as variáveis de crescimento, dentre as características físico-hídricas estudadas.

- Entre os solos superiores, para a maioria das variáveis de crescimento avaliadas foram verificados os maiores teores de K e P, pH mais elevado, maior saturação de bases e menor saturação por Al.

- As correlações das características químicas do solo com as variáveis de crescimento foram baixas. 


\section{REFERÊNCIAS}

BALLONI, E. A. Efeitos da fertilização mineral sobre o desenvolvimento de Pinus caribea Morelet var. bahamensis (Griseb) Barret et Golfari em solo de cerrado do Estado de São Paulo. $110 \mathrm{f}$. Dissertação (Mestrado) - Escola Superior de Agricultura “Luiz de Queiroz”, Universidade de São Paulo, Piracicaba, 1984.

BARTZ, H. R.; SIQUEIRA, A. O. J. F. de; BORKERT, C. M.; KOCHANN, R. A. Recomendações de adubação e calagem para os estados do Rio Grande do Sul e de Santa Catarina. 3. ed. Passo Fundo: SBCS - Núcelo Regional Sul, 1995. 224 p.

BELLOTE, A. F. J. Influência dos nutrientes minerais e dos atributos do solo sobre a produtividade, a estrutura anatômica e a densidade da madeira produzida pelo Pinus taeda. Piracicaba: USP, 2006. 96 p. Relatório Final de Pós-Doutorado em Engenharia Florestal.

CARVAlHO, A. P.; MENEGOL, O.; OliVEIRA, E. B. de; MACHADO, S. do A.; POTTER, R. O.; FASOLO, P. J.; FERREIRA, C. A.; BARTOSZECK, A. Efeitos de características do solo sobre a capacidade produtiva de Pinus taeda. Boletim da Pesquisa Florestal, Colombo, n. 39, p. 51-66. 1999.

CORREIA, J. R.; COSTA, L. M. da; NEVES, J. C. L.; CRUZ, C. D. Estudo do relacionamento entre características físicas e químicas do solo e a produtividade do gênero Pinus. Revista Árvore, Viçosa, MG, v. 20, n. 2, p. 161-169. 1996.

CROMER, R. N.; BARR, N. J.; WILliAMS, E. R.; McNAUGHT, A. M. Response to fertilizer in a Pinus radiata plantation: Aboveground biomass and wood density. New Zealand Journal of Forestry Science, Rotorua, v.15, p. 59-70. 1985.

DOLDAN, M. E. Q. Desenvolvimento da altura dominante de Pinus taeda L. como resposta aos estímulos dos fatores do meio, na região de Ponta Grossa. Floresta, Curitiba, v. 20, n. 1 e 2, p. 54-55. 1990.

EMBRAPA. Serviço Nacional de Levantamento e Conservação de Solos. Levantamento de reconhecimento dos solos do Estado do Paraná. Londrina: SNLCS/SUDESUL-IAPAR, 1984. 787 p. (EMBRAPA-SNLCS. Boletim de Pesquisa, n. 27).

EMBRAPA. Centro Nacional de Pesquisa de Solos. Manual de métodos de análise de solos. 2. ed. Rio de Janeiro: Embrapa. CNPS, 1997. 212 p. (Documento, n. 1).

EMBRAPA. Centro Nacional de Pesquisa de Solos. Sistema brasileiro de classificação de solos. Brasília: Embrapa. Produção de Informação, 1999. 412 p.

FERREIRA, C. A.; SIlvA, H. D. da; REISSMANN, C. B.; BELlOTE, A. F. J.; MARQUES, R. Nutrição de pinus no sul do Brasil. Colombo: Embrapa Florestas, 2001. 23 p. (Documentos, n. 60).

GREENLAND, D. J. (Ed.) Soil physical properties and crop production in the tropics. Chichester: J. Wiley \& Sons, 1979. p. 3-6.

HAAG, H. P. Nutrição mineral de Eucalyptus, Pinus, Araucaria e Gmelina no Brasil. Campinas: Fundação Cargill, 1983. 101 p.

HILLEL, D. Fundamentals of soil physics. New York: Academic, 1980. 413 p.

LAL, R. The role of physical properties in maintaining productivity of soils in the tropics. In: LAL, R.; GREENLAND, D.J. (Eds.). Soil physical properties and crop production in the tropics. New York: J. Wiley \& Sons, 1978 p. 7-44.

LASO GARICOITS, L. S. Estado nutricional e fatores do solo limitantes do crescimento de Pinus taeda L. em Telêmaco Borba. 128 f. Dissertação (Mestrado em Engenharia Florestal) - Universidade Federal do Paraná, Curitiba, 1990.

MENEGOL, O. Índice de sítio e relação entre altura dominante e teores nutricionais das acículas em povoamentos de Pinus elliottii var. elliottii no segundo planalto paranaense. 74 f. Dissertação 
(Mestrado em Ciências Florestais) - Setor de Ciências Agrárias, Universidade Federal do Paraná, Curitiba, 1991.

MUNIZ, P. J. C. da; BALDANZI, G.; PELliCO NETTO, S. de. Ensaio de adubação em Pinus elliotti e Pinus taeda no sul do Brasil. Revista Floresta, Curitiba, v. 6, n. 1, p. 5-13, 1975.

NAMBIAR-EKS; BROWN-AG. Towards sustained productivity of tropical plantations: science and practice. In: NAMBIAR-EKS (Ed.). Management of soil, nutrients and water in tropical plantation forests. Canberra: Australian Centre for International Agricultural Research, 1997. p. 527-553. (ACIAR Monograph, n. 43).

ORTEGA, A.; MONTEIRO, G. Evaluación de la calidad de las estaciones forestales. Ecologia, Madrid, n.2, p. 1-24, 1973.

PAROTTA, J. The role of plantation forests in rehabilitating degraded tropical ecosystems. Agriculture, Ecosystems and Environment, Amsterdam, n. 41, p. 115-133, 1992.

REISSMANN, C. B.; WISNIEWSKI, C. Aspectos nutricionais de plantios de Pinus. In: GONÇALVES, J. L. M.; BENEDETTI, V. Nutrição e fertilização florestal. Piracicaba: IPEF, 2000. p. 135-166.

RIGATTO, P. A.; DEDECEK, R. A.; MATOS, J. L. M. de. Influência dos atributos do solo sobre a qualidade da madeira de Pinus taeda para produção de celulose Kraft. Revista Árvore, Viçosa, MG, v. 28, n. 2, p. 267-273, 2004.

SNOWDON, P.; BENSON, M. L. Effects of combinations of irrigation and fertilization on the growth and above-ground biomass production of Pinus radiata. Forest Ecology and Management, Amsterdam, v. 52, n. 1/4, p. 87-116, 1992.

TOMÉ JÚNIOR, J. B. Manual para interpretação de análise de solo. Guaíba: Agropecuária, 1997. 247 p.

TIARKS, A.; NAMBIAR, E. K. S; COSSALTER, C. General background and research strategy. In: CIFOR. Workshop Site management and productivity in tropical plantations, 2., 1998, Pietermaritzburg. [Proceedings...]. Pietermaritzburg, South Africa. 1998. c. 3.11 p.

ZOBEL, B. J.; WYK, G. V.; STAHL, P. Growing exotic forest. New York: J. Wiley \& Sons. 1987. 508 p. 